\title{
Process Parameter Optimizing and Studies on Microstructure and Properties of AZ31 Alloy Prepared by Semisolid Rolling Process
}

\author{
Renguo GUAN ${ }^{\dagger}$, Zhanyong ZHAO, Xiang WANG, Chunguang DAI and Chunming LIU \\ School of Materials and Metallurgy, Northeastern University, Shenyang 110189, China \\ [Manuscript received 26 October 2012, in revised form 28 December 2012] \\ (c) The Chinese Society for Metals and Springer-Verlag Berlin Heidelberg
}

\begin{abstract}
A novel continuous semisolid rolling process for producing AZ31 alloy strip was developed. The process parameters were optimized, and microstructure and properties of AZ31 alloy prepared by the process were studied. The results reveal that primary grains of the strip become coarse, and the grain structure transforms from round shape to dendrite with the increment of casting temperature gradually. Eutectic phase fraction and primary grain size increase with the increment of roll speed. The primary grain size decreases firstly and then increases with the increment of the vibration frequency correspondingly. When the casting temperature is from $650{ }^{\circ} \mathrm{C}$ to $690{ }^{\circ} \mathrm{C}$, the roll speed is $0.069 \mathrm{~m} \cdot \mathrm{s}^{-1}$, and the vibration frequency is about $80 \mathrm{~Hz}, \mathrm{AZ3} 1$ alloy strip with a cross section size of $4 \mathrm{~mm} \times 160 \mathrm{~mm}$ was prepared by the proposed process. The ultimate tensile strength and elongation are improved $1 \%$ and $57 \%$, respectively.
\end{abstract}

\section{KEY WORDS: Semisolid; Sloping plate; Rolling; AZ31 alloy; Microstructure; Property}

\section{Introduction}

Because magnesium alloy materials have remarkable benefits for reducing the weight of structural parts, saving energy and avoiding toxicity, they are applied in automobile, aviation and electronics more and more widely ${ }^{[1,2]}$. However, the deformation ability of magnesium alloys is not high, which causes low production efficiency and high price of magnesium alloy products. In order to deal with these problems, semisolid metal processing was usually adopted ${ }^{[3]}$. Semisolid processing technique is developed because of its advantages of easy forming, good product microstructure and performances. Therefore, the semisolid processing is regard as an effective technique for magnesium alloy processing ${ }^{[4,5]}$. Up to now, many slurry preparation processes have been developed ${ }^{[6,7]}$. Among them, sloping plate process attracts more attentions because of its advantages of high efficiency

† Corresponding author. Prof., Ph.D.; Tel: +86 24 83681463; E-mail address: guanrg@smm.neu.edu.cn (Renguo GUAN)

DOI: $10.1007 / \mathrm{s} 40195-012-0190-5$ and low cost. In this process, the liquid alloy is cast onto a sloping plate. During the melt flow process, the alloy is cooled and stirred by the cooling sloping plate. Therefore, the semisolid slurry with fine spherical primary grains can be prepared. Motegi ${ }^{[8]}$, Kapranos et al..$^{[9]}$, Grimmig et al. ${ }^{[10]}$, Haga et al. ${ }^{[11]}$ and Guan et al. ${ }^{[12]}$ have carried out research works on this technique. However, how to produce strip and sheet of magnesium alloys by this technique have not been studied yet. In this paper, the vibrating sloping plate and the shape rolling mill were adopted, and a novel continuous semisolid rolling process for producing AZ31 alloy strip was developed. The process parameters were optimized, and microstructure and properties of AZ31 alloy prepared by the process were studied.

\section{Experimental}

As shown in Fig. 1, once the melt is cast onto the vibrating sloping plate surface, the melt nucleates rapidly under the strong cooling condition, and the primary grains grow into fine spherical structures un- 


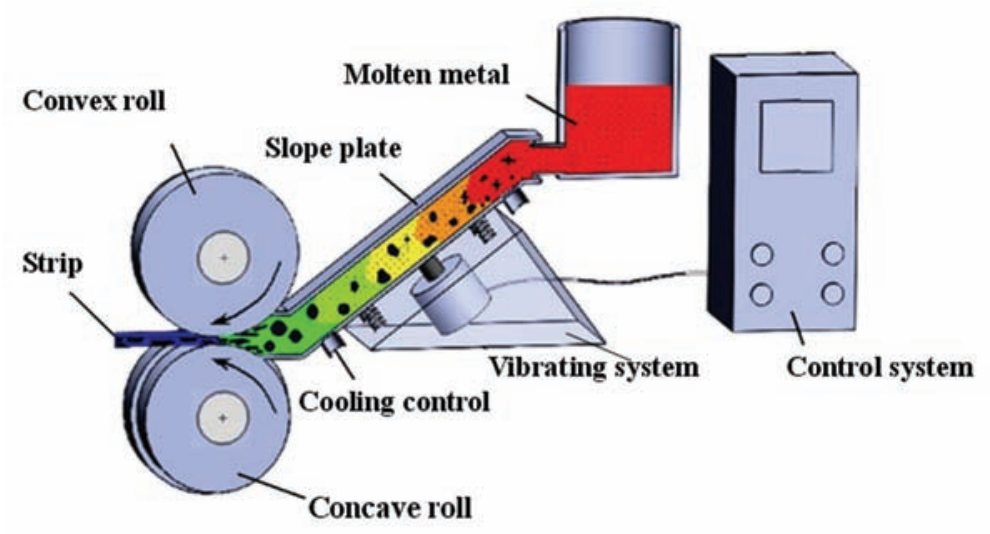

Fig. 1 The schematic diagram of the continuous semisolid rolling process

der stirrings of vibration and melt flow, so semisolid slurry can be prepared. Subsequently, the slurry flows into the roll gap whose broadsides are constrained by the convex and concave rolls, so the slurry is rolled by the shape rolling mill. This process has two main advantages. Firstly, the rolling speed of semisolid alloy is much higher than that of conventional liquid roll casting, so the process is expected to be developed as a high-speed roll-casting process. Secondly, the microstructure and the mechanical properties of the product are better than those of conventional roll casting.

The experimental equipment is the self-designed machine of continuous semisolid rolling process. The diameter of the rolls is $400 \mathrm{~mm}$, and the maximum rolling speed is $22 \mathrm{~m} \cdot \mathrm{min}^{-1}$. The rolls were cooled by circulating water. The cross section size of the AZ31 alloy strip is $4 \mathrm{~mm} \times 160 \mathrm{~mm}$. The experimental material was AZ31 alloy. The chemical compositions (mass \%) of the alloy are $\mathrm{Al} 3.0, \mathrm{Zn} \mathrm{1.0,} \mathrm{Mn} \mathrm{0.4,} \mathrm{Ni}$ $0.01, \mathrm{Fe} 0.01$ and $\mathrm{Mg}$ balanced. The microstructures of the strips produced under different process parameters were observed under an OLYMPUS PMG51 metallographic microscope. The average grain size was calculated by

$$
d=\frac{L_{\mathrm{T}}}{N \times n}
$$

where $d$ is the average grain size, $L_{\mathrm{T}}$ is the length of measure line, $N$ is the grain number that is covered by the measure line and $n$ is magnification value. The average roundness of the grain shape was calculated by

$$
S_{\mathrm{F}}=\frac{L_{\mathrm{p}}^{2}}{4 \pi A}
$$

where $S_{\mathrm{F}}$ is the average grain roundness, $L_{\mathrm{p}}$ is total circumference of the measured grains, and $A$ is total grain areas. The average grain size and the average roundness of the grain shape were measured by OLYCIA m3 image analysis software. At least 2000 grains were measured per sample. Three individual experiments were performed at each condition. The mechanical properties of the strip were measured by using a CMT5105 tensile testing machine.

\section{Results and Discussion}

\subsection{Effects of process parameters on microstructure of AZ31 alloy trip}

Fig. 2 shows the microstructures of AZ31 alloy strips on the cross section under different casting temperatures. Fig. 3 is the relationships of the casting temperature and the grain size and roundness. The results reveal that primary grains become coarse, and grain structure transforms from round shape to dendrite with the increment of casting temperature gradually. The grain size and roundness of AZ31 alloy strip increase with the increment of casting temperature. When the casting temperature is $650{ }^{\circ} \mathrm{C}$, the grain size is $23.1 \mu \mathrm{m}$, and the grain roundness is 1.7 . When the casting temperature increases from $670{ }^{\circ} \mathrm{C}$ to $690{ }^{\circ} \mathrm{C}$, the grain size increases from $27.6 \mu \mathrm{m}$ to $35.3 \mu \mathrm{m}$, and the grain roundness increasees from 1.9 to 2.9 , correspondingly. However, when the casting temperature is higher than $690{ }^{\circ} \mathrm{C}$, the change tendency of grain roundness becomes sharply. Canyook et al..$^{[13]}$ and Mehrara et al. ${ }^{[14]}$ reported that the heterogeneous nucleus on the plate surface and dendrite breakage caused microstructure refinement during sloping plate process. Besides, recent studies found that the thickness of velocity boundary layer is much smaller than that of temperature boundary during the sloping plate process, and temperature distributions in most of the melt are homogeneous ${ }^{[15]}$. At the same time, the cooling rate of the melt on water-cooling sloping plate is much larger than that of conventional casting ${ }^{[15]}$. Eruptive nucleation can easily happen under the above conditions ${ }^{[16]}$. Actually, heterogeneous nucleation and eruptive nucleation determine the microstructure of the strip. The nucleation rate of the two mechanisms is greatly affected by the casting temperature, and the nucleation rate usually increases with the decrease of the casting temperature. The $\mathrm{Mg}-\mathrm{Al}$ phase diagram shows that $\alpha-\mathrm{Mg}$ and $\beta-\mathrm{Mg}_{17} \mathrm{Al}_{12}$ are formed by a eutectic reaction under equilibrium solidification. The AZ31 magnesium alloy contains no precipitates under equilibrium solidification conditions. It is reported that $\beta-\mathrm{Mg}_{17} \mathrm{Al}_{12}$ 


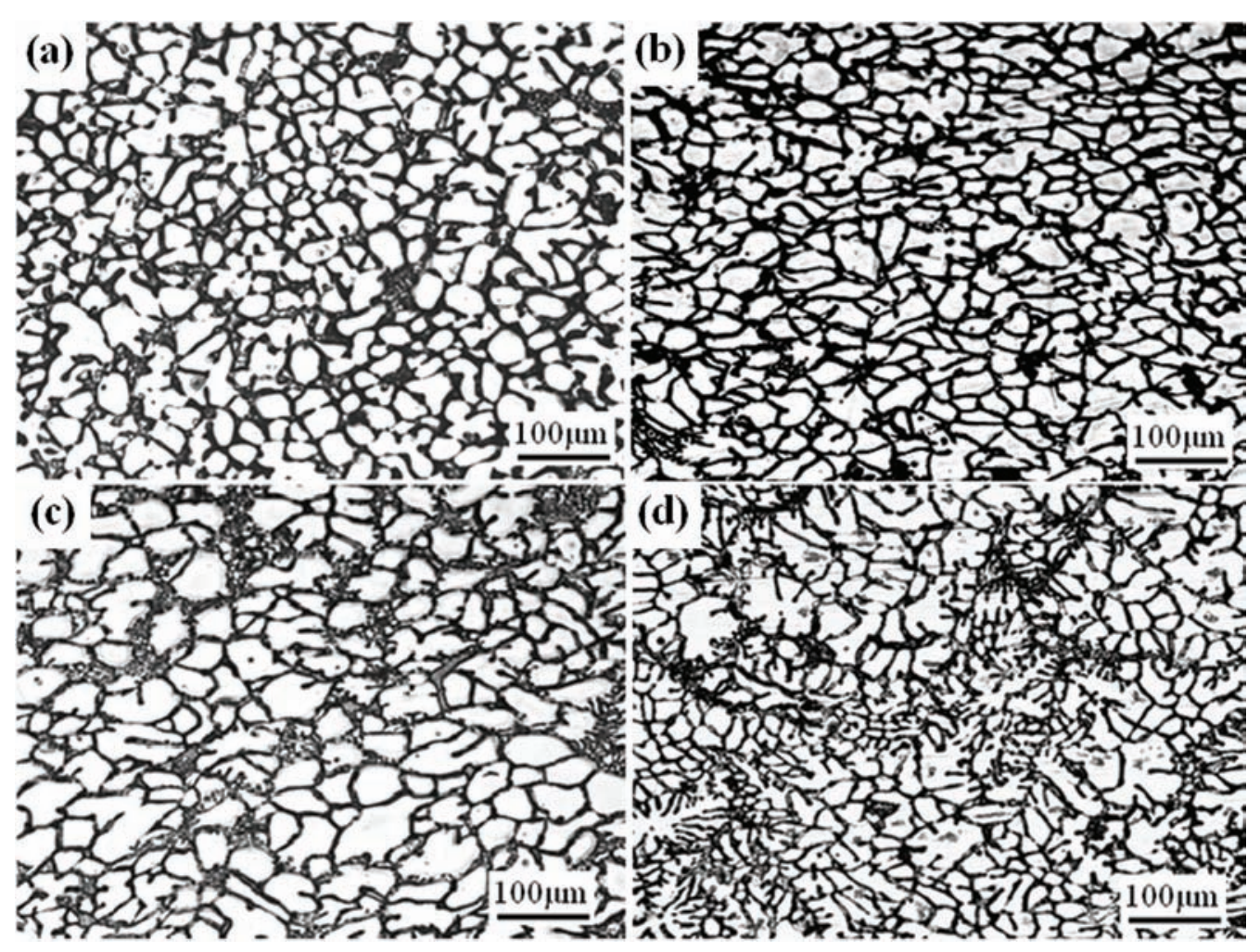

Fig. 2 The microstructures of AZ31 alloy strips on the cross section under different casting temperatures: (a) $650{ }^{\circ} \mathrm{C}$, (b) $670{ }^{\circ} \mathrm{C}$, (c) $690{ }^{\circ} \mathrm{C}$, (d) $705{ }^{\circ} \mathrm{C}$ (the roll speed is $0.069 \mathrm{~m} \cdot \mathrm{s}^{-1}$ )

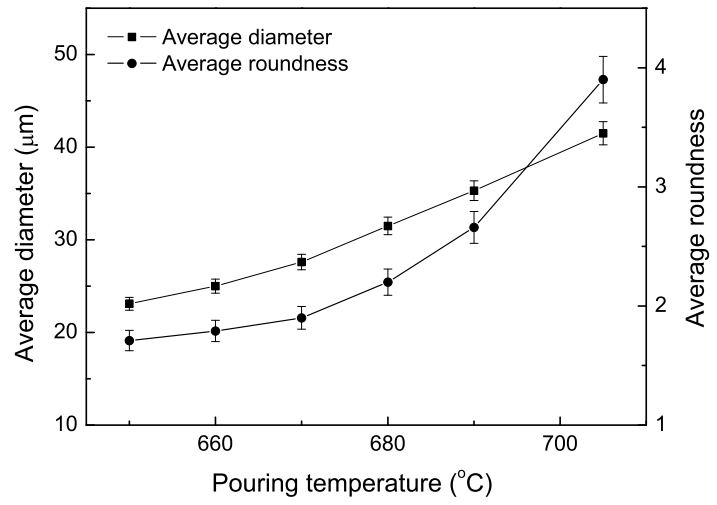

Fig. 3 Relationships of the casting temperature to the grain size and the roundness

and $\mathrm{Al}-\mathrm{Mn}$ formed at the grain boundaries in normally cast AZ31 magnesium alloy ${ }^{[17]}$. The cooling rate of the melt during semisolid rolling process is much larger than that of conventional casting, and the metal melt solidifies under non-equilibrium conditions. Thus, $\alpha$-Mg was formed first, and the divorced eutectic reaction occurred from the subsequent melt rich in $\mathrm{Al}$ such that the $\beta-\mathrm{Mg}_{17} \mathrm{Al}_{12}$ and $\mathrm{Al}-$ Mn phases were formed ${ }^{[18]}$. The second nucleation and crystallization of $\alpha$-Mg did not happened under rapid cooling in the roll gap, and the remnant liquids usually transform into eutectic phases. The primary grains ripening took place mainly in the roll gap, so the microstructure of the strip was mainly affected by the nucleation rate of the semisolid slurry prepared by the vibration sloping plate. Since the nucleation rate of the semisolid slurry increases with the decrease of the casting temperature, the grain size of the strip also decreases with the decrease of the casting temperature. When the casting temperature reached $705{ }^{\circ} \mathrm{C}$, the nucleation rate on the sloping plate was very small, and liquid fraction was too big in the roll gap. Therefore, the remnant liquid solidified into eutectic structure rapidly in the roll gap, and large dendrites and eutectic structures were remained in the strip, as shown in Fig. 2(d).

The microstructures of AZ31 alloy strips on cross section under different roll speeds are shown in Fig. 4. Fig. 5 shows the solid fraction comparison of the strips produced under different roll speeds. Fig. 6 is the grain size comparison of the strips produced under different roll speeds. The results reveal that the rolling speed influences eutectic phase fraction that transformed from the liquid phase in the roll gap under rapid cooling. When the roll speed was $0.087 \mathrm{~m} \cdot \mathrm{s}^{-1}$ and was relatively higher, the filling speed of semisolid slurry was also higher, so the cooling time of the melt on the sloping plate and in the roll gap was shorter. The nucleation rate of the melt was small correspondingly. The second nucleation and crystallization of $\alpha$-Mg did not happened under rapid cooling in the roll gap, so more remnant liquids transformed into eutectic phases. At the same time, 


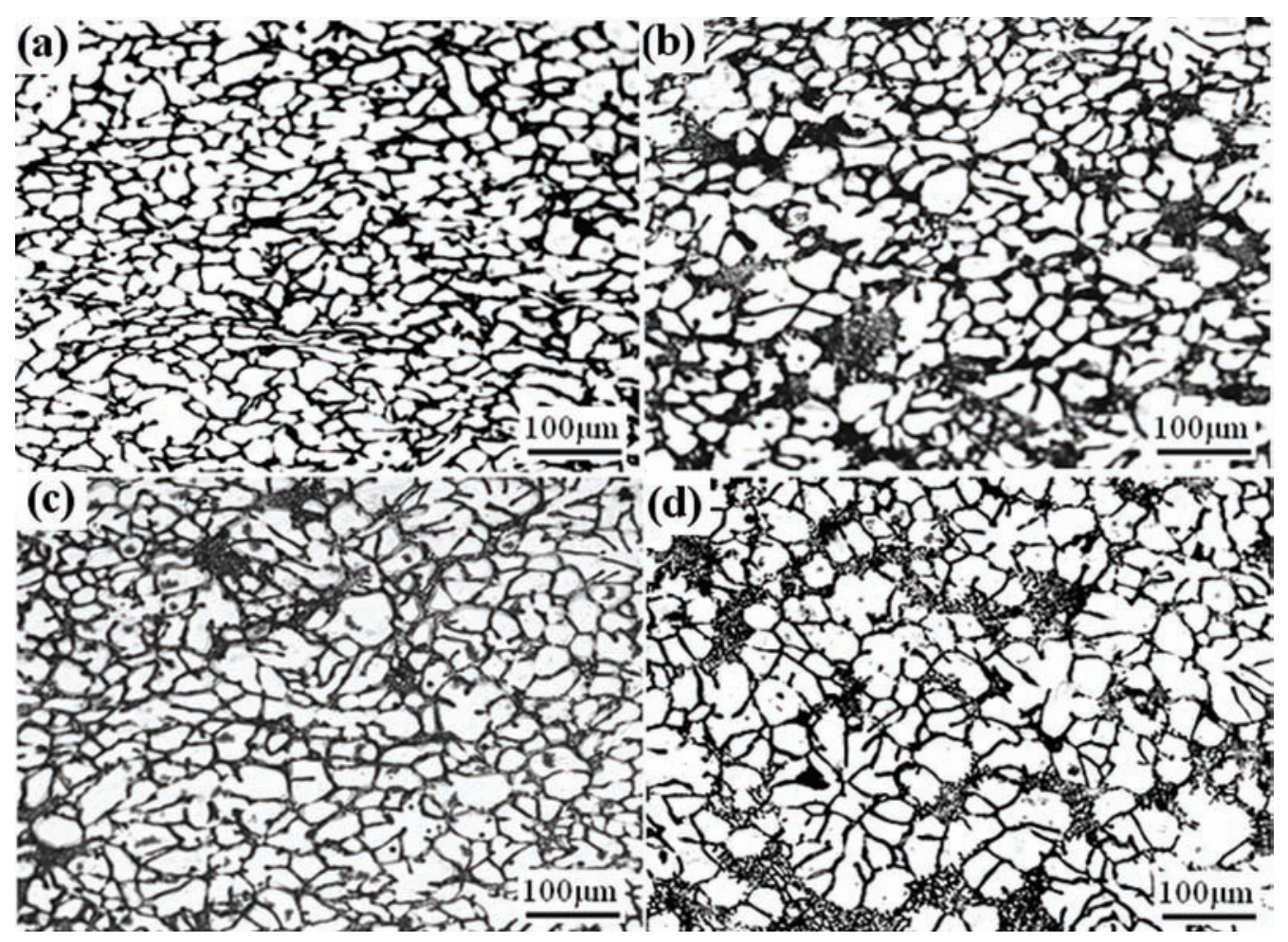

Fig. 4 Microstructures in the center of cross section of rheo-rolling sheets obtained at different linear speeds of working roll: (a) $670{ }^{\circ} \mathrm{C}, 0.069 \mathrm{~m} \cdot \mathrm{s}^{-1}$; (b) $670{ }^{\circ} \mathrm{C}, 0.087 \mathrm{~m} \cdot \mathrm{s}^{-1}$; (c) $690{ }^{\circ} \mathrm{C}, 0.069 \mathrm{~m} \cdot \mathrm{s}^{-1}$; (d) $690{ }^{\circ} \mathrm{C}$, $0.087 \mathrm{~m} \cdot \mathrm{s}^{-1}$

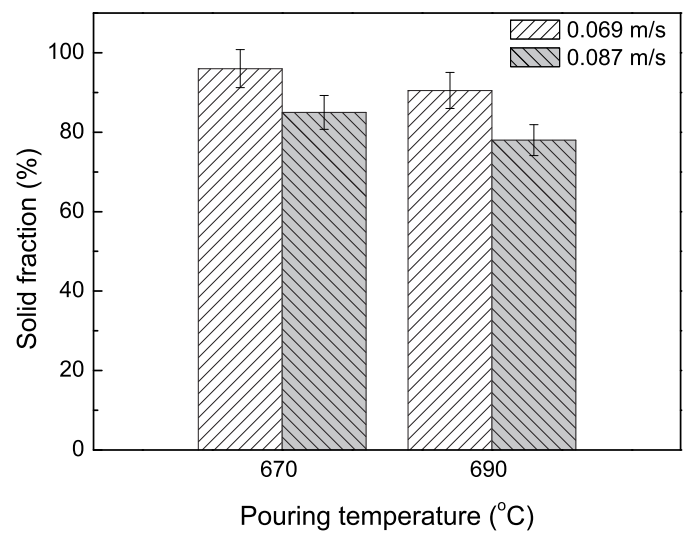

Fig. 5 Solid fraction comparsion of the strips produced under different roll speeds

the primary grains ripened into large spherical or rosette structures. Therefore, eutectic phase fraction and primary grain size increase with the increment of roll speed. When the roll speed was $0.069 \mathrm{~m} \cdot \mathrm{s}^{-1}$, the grain size and the eutectic phase fraction was small correspondingly. The optimized roll speed is $0.069 \mathrm{~m} \cdot \mathrm{s}^{-1}$.

The present work adopted a vibrating sloping plate. The aim is to avoid slurry adhesion on the plate surface and improve slurry quality. Vibration can accelerate stirring of the melt and is helpful to establish homogenous solute and temperature fields that are the ideal conditions for eruptive nucle-

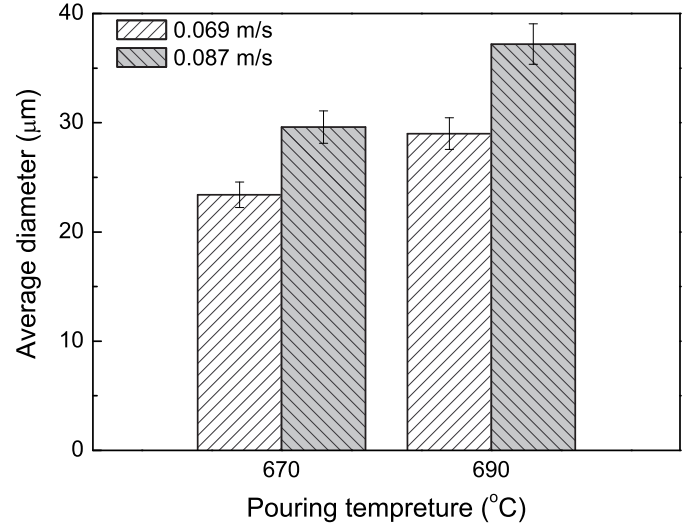

Fig. 6 Grain size comparsion of the strips produced under different roll speeds

ation. Moreover, vibration can accelerate the dendrite breakage and is helpful to refine grain size. The microstructures of AZ31 alloy strip produced under different vibration frequencies are shown in Fig. 7. Fig. 8 shows the relationship of the vibration frequency and the grain size. The primary grain size decreases firstly and then increases with the increment of the vibration frequency. The critical frequency is $80 \mathrm{~Hz}$. Stirring strength of the vibration can affect the grain size of the alloy. The stirring strength of the vibration depends on the dominant action of the vibration frequency or amplitude. The vibration frequency is related to the vibration amplitude. The relationship of the vibration frequency and amplitude of experimen- 

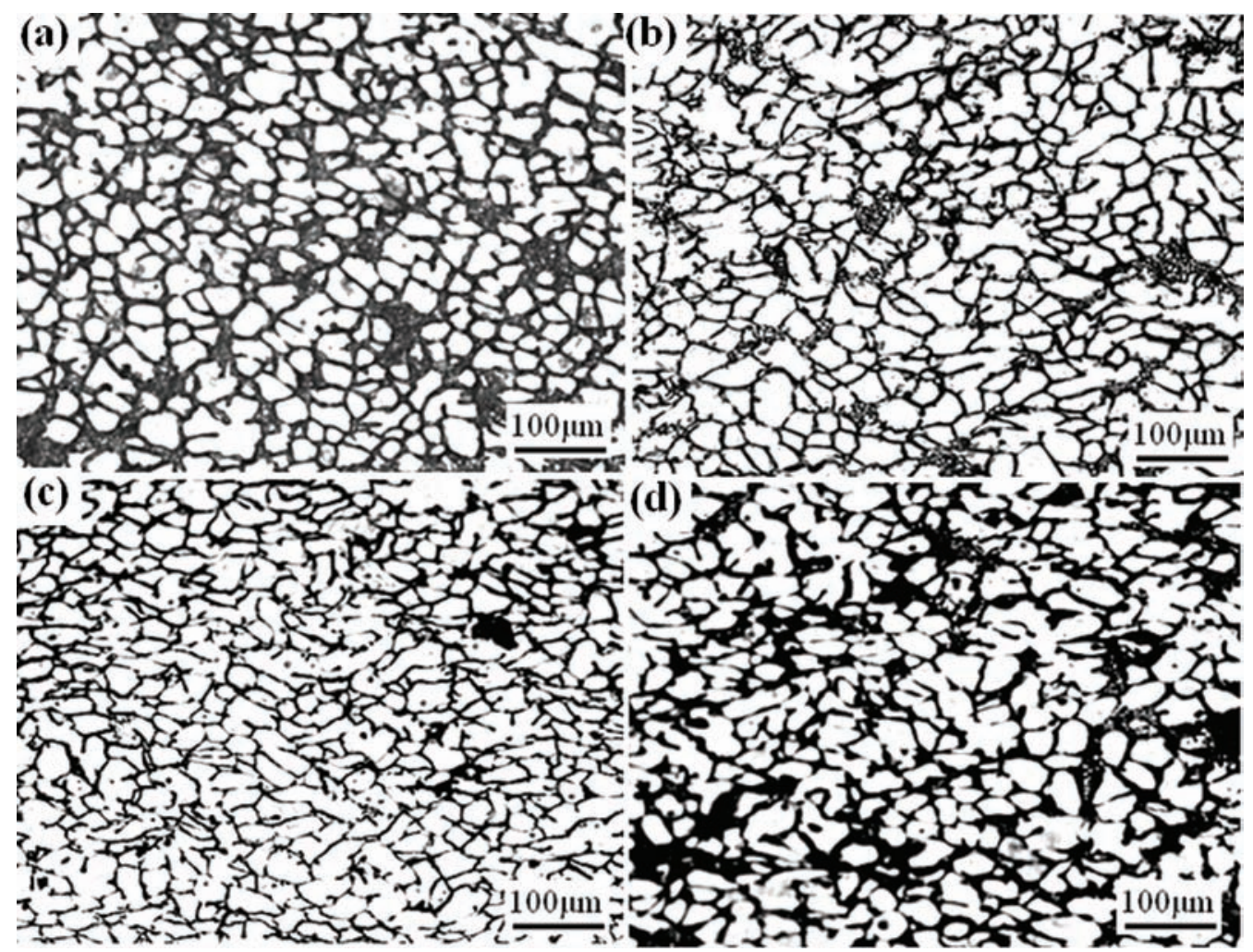

Fig. 7 The microstructures of AZ31 alloy strip produced under different vibration frequencies: (a) $30 \mathrm{~Hz}$; (b) $60 \mathrm{~Hz}$; (c) $80 \mathrm{~Hz}$; (d) $100 \mathrm{~Hz}$ (casting temperature is $670{ }^{\circ} \mathrm{C}$, roll speed is $0.069 \mathrm{~m} \cdot \mathrm{s}^{-1}$ )

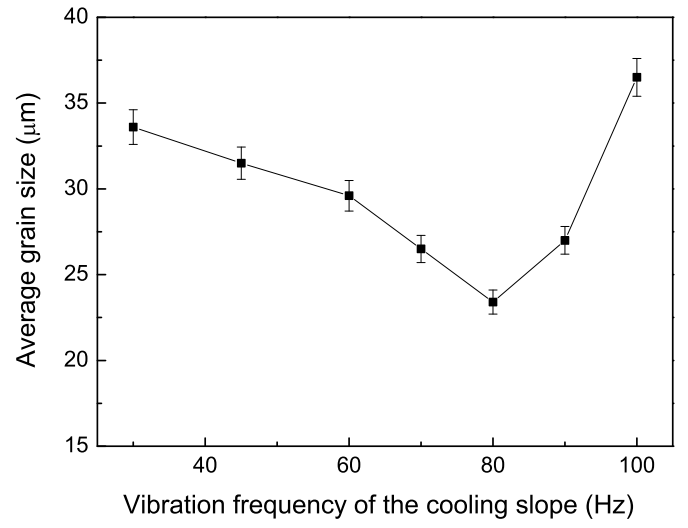

Fig. 8 The relationship of vibration frequency and grain size

tal device is shown in Fig. 9. The vibration amplitude decreases with the increment of vibration frequency. When the vibration frequency is lower than $80 \mathrm{~Hz}$, the frequency dominates the stirring strength. Once the vibration frequency is higher than $80 \mathrm{~Hz}$, the amplitude becomes the dominant factor that determines the stirring strength, and the grain size varies correspondingly, as shown in Fig. 8.

\subsection{Optimized process parameters, microstructure and properties of the product}

The optimized process parameters suggested are

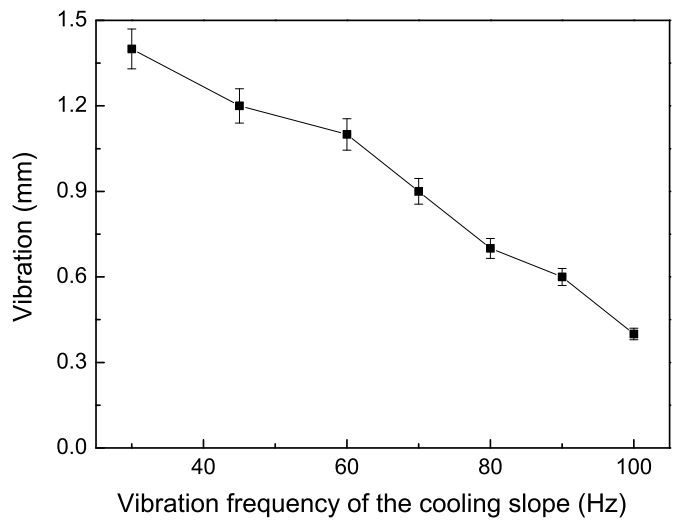

Fig. 9 The relationship between vibration frequency and amplitude

that the casting temperature is from $650{ }^{\circ} \mathrm{C}$ to $690{ }^{\circ} \mathrm{C}$. The roll speed is $0.069 \mathrm{~m} \cdot \mathrm{s}^{-1}$, and the vibration frequency is $80 \mathrm{~Hz}$. Under these parameters, AZ31 alloy strip with a cross section size of $4 \mathrm{~mm} \times 160 \mathrm{~mm}$ was prepared by the process, as shown in Fig. 10(a). The three dimensional microstructures of the strip is shown in Fig. 10(b). The microstructure is mainly composed of fine spherical or rosette grains, and the average grain size of the strip is $23.4 \mu \mathrm{m}$. The tensile results show that the average ultimate tensile strength along the rolling direction of AZ31 alloy strip is $232 \mathrm{MPa}$, and the average elongation is $6.3 \%$. The mechanical property comparison of the present product and the 


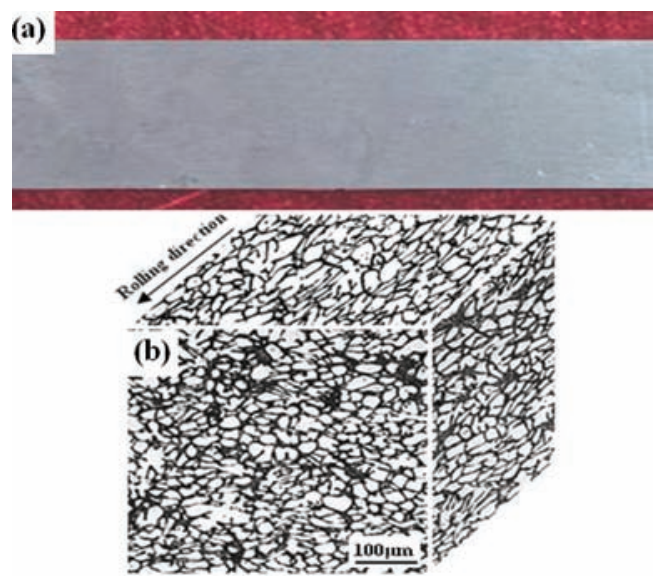

Fig. 10 AZ31 alloy strip and its microstructures obtained at the casting temperature of $670{ }^{\circ} \mathrm{C}$ : (a) AZ31 alloy strip; (b) microstructure of the product

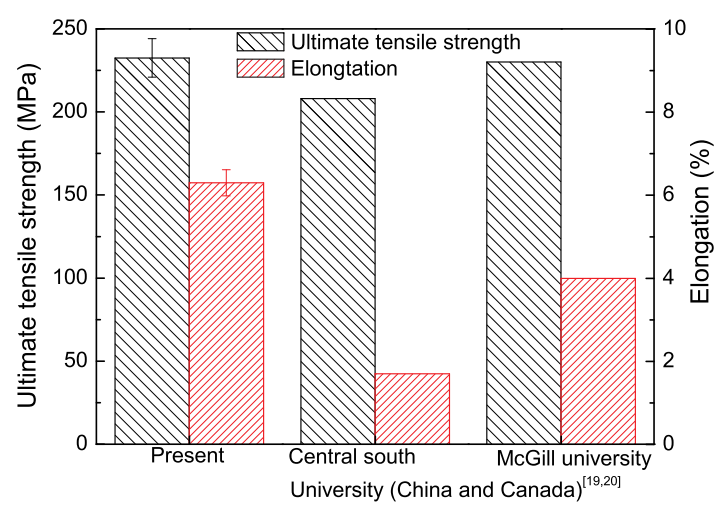

Fig. 11 Comparison of the properties along the rolling direction of AZ31 alloy strips produced by the present process and conventional roll casting

strips prepared by previous studies is shown in Fig. 11. Generally, the ultimate tensile strength of AZ31 alloy strip produced by the roll casting is about from $200 \mathrm{MPa}$ to $230 \mathrm{MPa}$, and the elongation is from $1 \%$ to $5 \%[19,20]$. Therefore, the ultimate tensile strength and elongation are improved $1 \%$ and $57 \%$ respectively.

\section{Conclusions}

(1) A novel continuous semisolid rolling process for producing AZ31 alloy strip was developed.

(2) Primary grains of the strip become coarse, and grain structure transforms from round shape to dendrite with the increment of casting temperature gradually.

(3) Eutectic phase fraction and primary grain size increase with the increment of roll speed.

(4) When the vibration frequency is lower than $80 \mathrm{~Hz}$, the frequency dominates the stirring strength. Once the vibration frequency is higher than $80 \mathrm{~Hz}$, the amplitude becomes the dominant factor. The primary grain size decreases firstly and then increases with the increment of vibration frequency correspondingly.

(5) When the casting temperature is from $650{ }^{\circ} \mathrm{C}$ to $690{ }^{\circ} \mathrm{C}$, the roll speed is $0.069 \mathrm{~m} \cdot \mathrm{s}^{-1}$ and the vibration frequency is about $80 \mathrm{~Hz}$, AZ31 alloy strip with a cross section size of $4 \mathrm{~mm} \times 160 \mathrm{~mm}$ was prepared by the proposed process. The ultimate tensile strength and elongation are improved $1 \%$ and $57 \%$ respectively.

\section{Acknowledgements}

This work was financially supported by the National Natural Science Foundation for Outstanding Young Scholars of China (No. 51222405), the National Natural Science Foundation of China (No. 51034002), and the Fok Ying-Tong Education Foundation (No. 132002), and the National Basic Research Program of China (No. 2011CB610405)

\section{REFERENCES}

[1] K. Yu, W.X. Li, R.C. Wang and Z.Q. Ma, Chin. J. Nonferr. Met. 13 (2003) 277. (in Chinese)

[2] S.S. Wu, D.N. Li, Y.W. Mao, X.J. Song, G.Z. Wu and J.R. Luo, Foundry 51 (2002) 583. (in Chinese)

[3] M.C. Flemings, R.G. Riek and K.P. Young, Mater. Sci. Eng. A 25 (1976) 103.

[4] E. Giraud, M. Suery and M. Coret, Metall. Mater. Trans. A 42 (2011) 3370.

[5] H. Moeller, G. Govender, W.E. Stumpf and R.D. Knutsen, Int. J. Cast. Met. Res. 22 (2009) 417.

[6] R. Haghayeghia, E.J. Zoquib, N.R. Greenc and H. Bahaia, J. Alloys Compd. 502 (2010) 382.

[7] X.L. Zhang, T.J. Li, S.S. Xie, T.M. Wang, Z.Q. Cao and J.Z. Jin, Rare Met. Mater. Eng. 38 (2009) 1495. (in Chinese)

[8] T. Motegi, Int. J. Mater. Prod. Technol. 2 (2001) 468.

[9] P. Kapranos, D.H. Kirkwood, H.V. Atkinson, J.T. Rheinlander, J.J. Bentzen, P.T. Toft, C.P. Debel, G. Laslaz, L. Maenner, S. Blais, J.M. Rodriguez-Ibabe, L. Lasa, P. Giordano, G. Chiarmetta and A. Giese, J. Mater. Process. Technol. 135 (2003) 271.

[10] T. Grimmig, A. Ovcharov, C. Afrath, M. Bunck and A. Buhrig-Polaczek, Diffus. Defect Data Part B 116117 (2006) 484.

[11] T. Haga, K. Tkahshi, M. Ikawaand and H. Watari, J. Mater. Process. Technol. 153-154 (2004) 42.

[12] R.G. Guan, Z.H. Xing, L. Shi, C. Wang and Y. Wang, Mater. Sci. Forum. 561-565 (2007) 865.

[13] R. Canyook, S. Petsut, S. Wisutmethangoon, M.C. Flemings and J. Wannasin, Trans. Nonferr. Met. Soc. Chin. 20 (2010) 1649.

[14] H. Mehrara, M. Nili-Ahmadabadi, B. Heidarian, S. Ashouri and J. Ghiasinejad, Diffus. Defect Data Part B 141-143 (2008) 785.

[15] R.G. Guan, Z.Y. Zhao, H. Zhang, C. Lian, C.S. Lee, C.M. Liu, J. Mater. Process. Technol. 212 (2012) 1430.

[16] R.G. Guan, F.R. Cao, L.Q. Chen, J.P. Li and C. Wang, J. Mater. Process. Technol. 209 (2009) 2592.

[17] H.Z. Ye and X.Y. Liu, J. Alloys Compd. 419 (2006) 54.

[18] H. Zhao, P.J. Li and L.J. He, J. Mater. Process. Technol. 212 (2012) 1670.

[19] X.F. Tan, D.H. Mao, L. Qiu and S.F. Zhang, Chin. Mech. Eng. 21 (2010) 2865. (in Chinese)

[20] M. Masoumi, F. Zarandi and M. Pekguleryuz, Mater. Sci. Eng. A 528 (2011) 1268. 